\title{
Endocrine assays in female patient with relapsing thymus cyst and myasthenia gravis
}

Authors M.Carsote, D.Terzea, I.Baciu, A.Mihai, D.Peretianu, F.Vasilescu, M.Popescu, R.Trifanescu, A.Dumitrascu, C.Poiana

Hospital "C.Davila” University of Medicine and Pharmacy, Bucharest, Romania; "C.I.Parhon" National Institute of Endocrinology, Bucharest, Romania; "SCM Povernei" Medical Centre, Bucharest, Romania; "Monza" Hospital, Bucharest, Romania

\section{Introduction}

The congenital cystic neck masses underlie various diagnosis including tymic cysts. Even they are an embryological defects, the adult onset might be seen. The aetiology is not clearly established. The malignant behaviour or infections are correlated to the cysts.

We present a female case with a complicated history of cysts

This is a case report.

\section{2-year old female is known with the following medical history.}

Seven years ago she was operated for a pericardia cyst.

The computed tomography was normal after surgery until 2014 when she accused breathing difficulties.

The computed tomography was performed and a tymic cyst was discovered (of $7 \mathrm{~cm}$ ).

Thoracotomy was chosen as procedure for the cyst: the cyst was partial evacuated during the procedure and then removed but the thymus was conserved.

The pathological exam confirmed a simple thymic cyst, with no atypia.

\section{Results:}

After surgery, the patient felt well for about six months when she accused again troubles in breathing, and also persistent asthenia.

The computed tomography found again the tymic cyst of 4.89 by 4.1 by $6.4 \mathrm{~cm}$, with no other thoracic or cervical anomalies.

The patient was referred for an endocrinologic check up. The blood pressure was 100 by $65 \mathrm{mmHg}$.

The normal TSH (of $1.5 \mu \mathrm{Ul} / \mathrm{mL}$ ) was associated with negative thyroid antibodies.

The morning plasma cortisol was of $19 \mu \mathrm{g} / \mathrm{dL}$ (normal levels less than $21 \mu \mathrm{g} / \mathrm{dL}$ ).

The calcium levels and parathormon, as well as basal plasma metanephrines / normetanephrines were also normal.

The prolactin levels were mildly increased (of $28 \mathrm{ng} / \mathrm{mL}$, normal levels less than $21 \mathrm{ng} / \mathrm{mL}$ ).

No pituitary anomaly was detected.

The patient was referred to neurological tests and myasthenia gravis was confirmed.

A second procedure for the thymus cyst is soon to be done, including the entire organ resection. The patient still delays it.

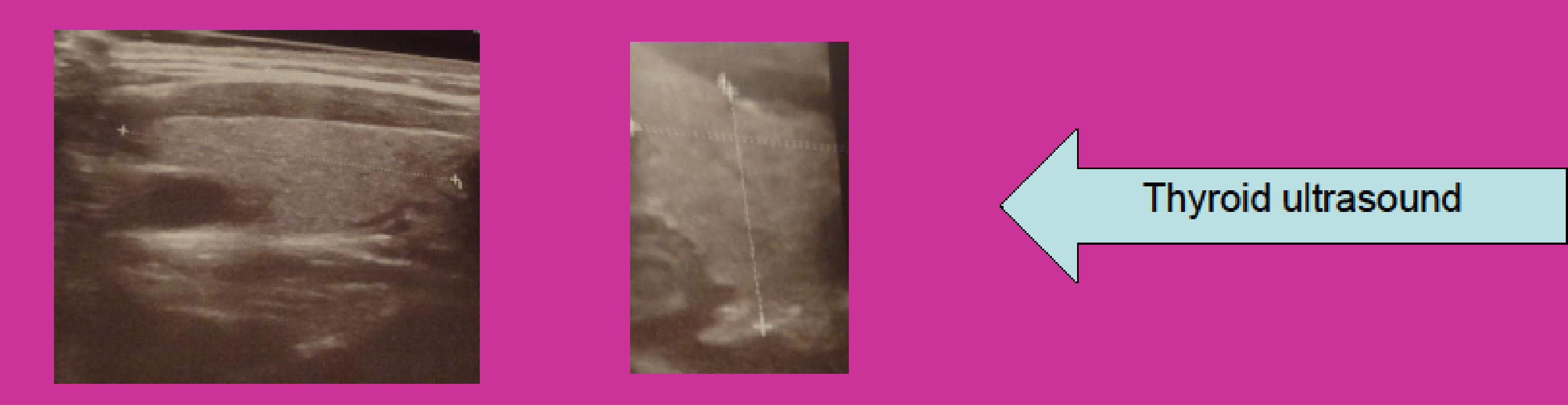

\section{Conclusions:}

The mildly increased prolactin levels are most probably associated to the thoracic surgery.

The complete resection of the thymus is encouraged in case of cysts, especially large ones, because of relapse risk.

The thymus anomalies bring together a large number of different medical specialities thus the therapeutic approach is multidisciplinary.
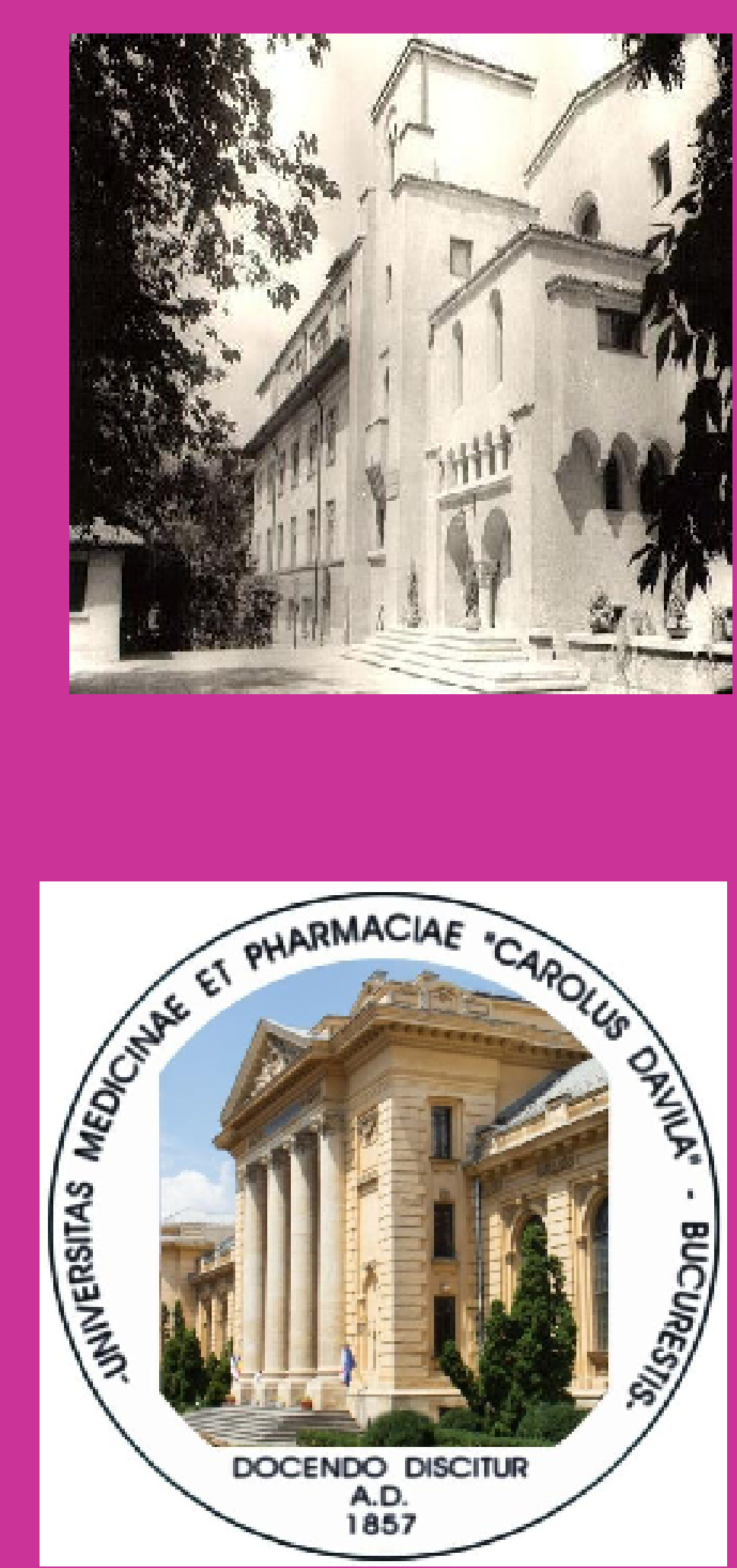